\title{
High-Performance Top-Gate Thin-Film Transistor with an Ultra-Thin Channel Layer
}

\author{
Te Jui Yen ${ }^{1}$, Albert Chin ${ }^{1, *}$ and Vladimir Gritsenko ${ }^{2,3,4}$ \\ 1 Department of Electronics Engineering, National Chiao Tung University, Hsinchu 300, Taiwan; \\ yenrick42269.ee05g@g2.nctu.edu.tw \\ 2 Rzhanov Institute of Semiconductor Physics, Siberian Branch, Russian Academy of Sciences, \\ 630090 Novosibirsk, Russia; grits@isp.nsc.ru \\ 3 Novosibirsk State University, 630090 Novosobirsk, Russia \\ 4 Novosibirsk State Technical University, 630020 Novosibirsk, Russia \\ * Correspondence: achin@nctu.edu.tw; Tel.: +886-3-5731841
}

Received: 3 October 2020; Accepted: 24 October 2020; Published: 28 October 2020

\begin{abstract}
Metal-oxide thin-film transistors (TFTs) have been implanted for a display panel, but further mobility improvement is required for future applications. In this study, excellent performance was observed for top-gate coplanar binary $\mathrm{SnO}_{2}$ TFTs, with a high field-effect mobility $\left(\mu_{F E}\right)$ of $136 \mathrm{~cm}^{2} / \mathrm{Vs}_{\text {, }}$ a large on-current/off-current $\left(\mathrm{I}_{\mathrm{ON}} / \mathrm{I}_{\mathrm{OFF}}\right)$ of $1.5 \times 10^{8}$, and steep subthreshold slopes of $108 \mathrm{mV} / \mathrm{dec}$. Here, $\mu_{F E}$ represents the maximum among the top-gate TFTs made on an amorphous $\mathrm{SiO}_{2}$ substrate, with a maximum process temperature of $\leq 400{ }^{\circ} \mathrm{C}$. In contrast to a bottom-gate device, a top-gate device is the standard structure for monolithic integrated circuits (ICs). Such a superb device integrity was achieved by using an ultra-thin $\mathrm{SnO}_{2}$ channel layer of $4.5 \mathrm{~nm}$ and an $\mathrm{HfO}_{2}$ gate dielectric with a $3 \mathrm{~nm} \mathrm{SiO} 2$ interfacial layer between the $\mathrm{SnO}_{2}$ and $\mathrm{HfO}_{2}$. The inserted $\mathrm{SiO}_{2}$ layer is crucial for decreasing the charged defect scattering in the $\mathrm{HfO}_{2}$ and $\mathrm{HfO}_{2} / \mathrm{SnO}_{2}$ interfaces to increase the mobility. Such high $\mu_{F E}$, large $\mathrm{I}_{\mathrm{ON}}$, and low $\mathrm{I}_{\mathrm{OFF}}$ top-gate $\mathrm{SnO}_{2}$ devices with a coplanar structure are important for display, dynamic random-access memory, and monolithic three-dimensional ICs.
\end{abstract}

Keywords: thin-film transistor; $\mathrm{SnO}_{2}$; TFT; integrated circuit; monolithic; 3D IC; brain-mimic

\section{Introduction}

The development of high-performance transistors has been continuously pursued for more than seven decades, since the transistor was invented in 1947. The metal-oxide thin-film transistor (TFT) was invented in 1964 [1], and had the important merits of low-temperature fabrication, a simple process for mass production, and visible light transparency [1-26]. Moreover, metal-oxide TFTs have widely diverse applications, such as in active matrix organic light emitting diodes [2,3], flexible electronics [4-7], and gas sensors [8-10]. By applying a high-mobility channel material and high-dielectric-constant (high-к) gate dielectric, metal-oxide TFT can also be used in high-speed low-power monolithic three-dimensional (3D) integrated circuits (ICs) [11-16]. Furthermore, the wide energy bandgap, excellent field-effect mobility $\left(\mu_{F E}\right)$ at high temperatures, and low leakage current of metal-oxide TFTs are especially important for high-temperature electronics [17] and dynamic random-access memory (DRAM) access transistors. In this paper, we report a top-gate $\mathrm{SnO}_{2}$ TFT that uses a combined $\mathrm{HfO}_{2}$ and $\mathrm{SiO}_{2}$ stack as a gate dielectric layer and an $\mathrm{SnO}_{2}$ channel layer. The top-gate TFT structure is more favorable than the bottom-gate device, owing to its high performance and easy integration in forming an IC. This top-gate device, with an $\mathrm{SiO}_{2}$ interfacial layer between $\mathrm{HfO}_{2}$ and $\mathrm{SnO}_{2}$, exhibited an excellent device performance, with a remarkably high $\mu_{F E}$ of $136 \mathrm{~cm}^{2} / \mathrm{Vs}$, a large on-/off-current $\left(\mathrm{I}_{\mathrm{ON}} / \mathrm{I}_{\mathrm{OFF}}\right)$ of $1.5 \times 10^{8}$, a sharp subthreshold slope $(\mathrm{SS})$ of $108 \mathrm{mV} / \mathrm{dec}$, and a much better resistance 
to moisture than the bottom-gate $\mathrm{SnO}_{2}$ TFT. Here, the $\mathrm{SiO}_{2}$ interfacial layer with a thickness of $3 \mathrm{~nm}$ is the key factor in decreasing the charged defect scattering inside $\mathrm{HfO}_{2}$ and increasing the $\mu_{F E}$. Such high-performance TFTs are crucial for future-generation high-resolution displays, DRAM access transistors, high interconnect-density monolithic 3D ICs, and 3D brain-mimicking ICs [11-13], where the down-scaling of silicon ICs is expected to be ended at an equivalent node around $1 \mathrm{~nm}$ within ten years.

\section{Materials and Methods}

P-type silicon wafers with $\sim 10$ ohmic-cm resistivity were used as substrates. A standard IC cleaning process was applied to remove the particles and native oxide from the silicon substrate. Then, an $\mathrm{SiO}_{2}$ layer with a thickness of $300 \mathrm{~nm}$ was formed on the substrate, and was used as an inter-metal-dielectric layer of the IC. Thereafter, a $4.5 \mathrm{~nm} \mathrm{SnO}_{2}$ layer was deposited through reactive sputtering with a $\mathrm{Sn}$ target under a pressure of $7.6 \times 10^{-3}$ torr, a mixture of $\mathrm{O}_{2} / \mathrm{Ar}$ gas flow at 20/24 sccm, and a DC power of $50 \mathrm{~W}$. The deposited $\mathrm{SnO}_{2}$ layer was subjected to post-annealing at $350{ }^{\circ} \mathrm{C}$ in ambient air for $30 \mathrm{~min}$. Next, $30 \mathrm{~nm}$ low work function aluminum Schottky source and drain electrodes [27,28] were deposited and patterned. Subsequently, a $3 \mathrm{~nm} \mathrm{SiO} 2$ layer and a $50 \mathrm{~nm}$ high- $\mathrm{k} \mathrm{HfO}_{2}$ gate dielectric were deposited on the $\mathrm{SnO}_{2}$ layer through physical vapor deposition. Finally, a $30 \mathrm{~nm} \mathrm{Ni}$ top-gate electrode was created using electron-beam evaporation and patterning. The gate length and width are 50 and $400 \mu \mathrm{m}$, respectively. Material analyses through X-ray photoelectron spectroscopy (XPS), secondary ion mass spectrometry (SIMS), and high-resolution transmission electron microscopy (TEM) were performed using Thermo Nexsa (Thermo Fisher Scientific Inc., Waltham, MA, USA), CAMECA IMS-6fE7 (CAMECA, Gennevilliers, France), and FEI Talos F200X (FEI company, Hillsboro, OR, USA), respectively. The electrical characterization of the device was measured using the HP4155B semiconductor parameter analyzer (HP, Englewood, CO, USA) and a probe station.

\section{Results and Discussion}

Figure 1a presents the drain-source current versus gate-source voltage $\left(I_{D S}-V_{G S}\right)$ characteristics of the top-gate TFTs with and without the $\mathrm{SiO}_{2}$ interfacial layer between the $\mathrm{SnO}_{2}$ channel and the $\mathrm{HfO}_{2}$ gate dielectric. The devices, with and without the ultra-thin $\mathrm{SiO}_{2}$, exhibit good $\mathrm{I}_{\mathrm{ON}} / \mathrm{I}_{\mathrm{OFF}} \mathrm{S}$ of $1.5 \times 10^{8}$ and $1 \times 10^{8}$, respectively, and sharp turn-on SS values of 108 and $117 \mathrm{mV} / \mathrm{dec}$, respectively. The interface trap density $\left(D_{i t}\right)$ can be calculated from SS [29,30]:

$$
D_{i t}=\frac{1}{q}\left(\frac{S S}{k T / q \times \ln 10}-1\right) C_{o x}-\frac{C_{d e p}}{q},
$$

where $C_{d e p}$ is the depletion capacitance. A $D_{i t}$ of $5.5 \times 10^{12} \mathrm{eV}^{-1} \mathrm{~cm}^{-2}$ is obtained, which is higher than the high-K/silicon transistor. Further interface improvement can increase the $S S$ and $\mu_{F E}$.

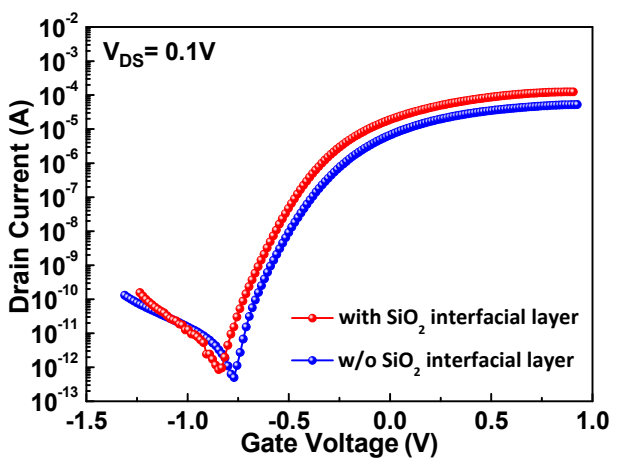

(a)

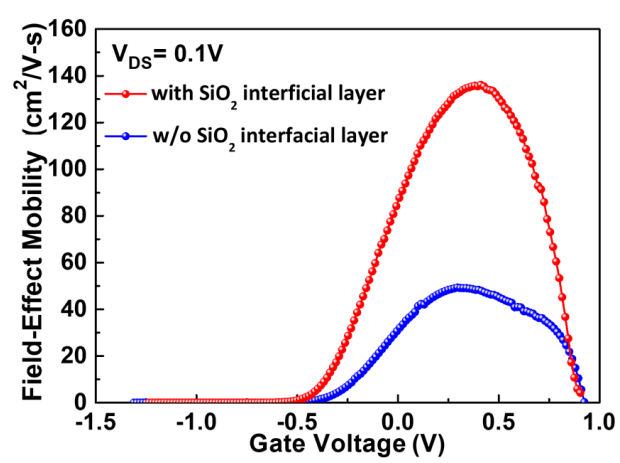

(b)

Figure 1. (a) $I_{D S}-V_{G S}$ and (b) $\mu_{F E}-V_{G S}$ characteristics of the top-gate $\mathrm{SnO}_{2}$ TFTs with and without an $\mathrm{SiO}_{2}$ interfacial layer. 
Figure $1 \mathrm{~b}$ depicts the $\mu_{F E}-V_{G S}$ characteristics of these devices. The $\mu_{F E}$ was obtained by a standard method used in silicon IC from the trans-conductance $\left(g_{m}\right)$ at a small $V_{D S}$ of $0.1 \mathrm{~V}$ :

$$
\mu_{F E}=\frac{g_{m}}{\left(W_{G} / L_{G}\right) C_{o x} V_{D S}},
$$

where $W_{G}, L_{G}$, and $C_{o x}$ are the gate width, gate length, and oxide capacitance, respectively. The $C_{o x}$ was obtained from the measured $C-V$ characteristics divided by the area of the $\mathrm{Ni} / \mathrm{HfO}_{2} / \mathrm{SiO}_{2} / \mathrm{Al} \mathrm{MIM} \mathrm{device}$ on the same chip. The $\mathrm{SnO}_{2}$ TFT with an $\mathrm{SiO}_{2}$ interfacial layer has a $\mu_{F E}$ as high as $136 \mathrm{~cm}^{2} / \mathrm{Vs}$, which is significantly higher than the $49.3 \mathrm{~cm}^{2} / \mathrm{Vs}$ for the device without the $\mathrm{SiO}_{2}$ layer. This is the highest $\mu_{F E}$ value for top-gate TFTs made on an amorphous $\mathrm{SiO}_{2}$ substrate and processed at a temperature of $\leq 400{ }^{\circ} \mathrm{C}$ [21-25].

To understand the significantly better the $I_{D S}$ and $\mu_{F E}$ data for TFTs with an ultra-thin $\mathrm{SiO}_{2}$ layer, we further measured the gate-source current versus gate-source voltage $\left(I_{G S}-V_{G S}\right)$ characteristics. As shown in Figure 2a, the gate leakage current does not demonstrate a significant difference between these two devices because the interfacial $\mathrm{SiO}_{2}$ layer was only $3 \mathrm{~nm}$ thick, and much thinner than the high- $\mathrm{K} \mathrm{HfO}_{2}$, which had a thickness of $50 \mathrm{~nm}$. The $I_{D S}$ versus the drain-source voltage $\left(I_{D S^{-}} V_{D S}\right)$ characteristics are presented in Figure 2b. The TFT device with the ultra-thin $\mathrm{SiO}_{2}$ layer exhibits a higher $\mathrm{I}_{D S}$ than the TFT without it, which is consistent with the $I_{D S^{-}} V_{G S}$ and $\mu_{F E^{-}} V_{G S}$ data presented in Figure 1a,b, because the higher $I_{D S}$ leads to a higher $\mu_{F E}$ value.

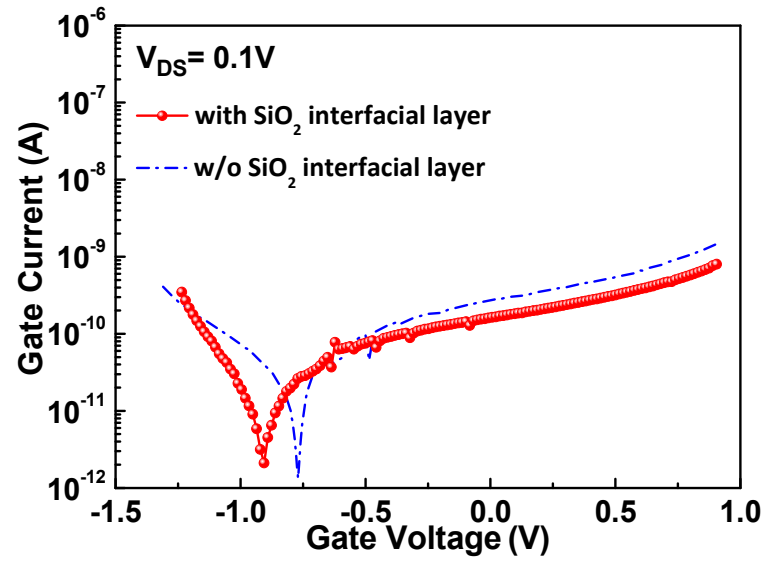

(a)

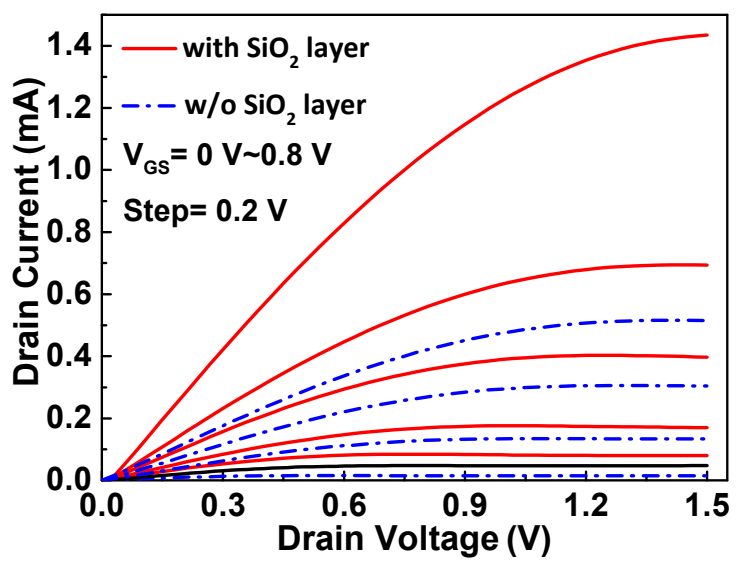

(b)

Figure 2. (a) $I_{G S}-V_{G S}$ and (b) $I_{D S}-V_{D S}$ characteristics of the top-gate $\mathrm{SnO}_{2}$ with and without an $\mathrm{SiO}_{2}$ interfacial layer.

An XPS analysis was performed on both the $\mathrm{HfO}_{2} / \mathrm{SiO}_{2} / \mathrm{SnO}_{2}$ and the $\mathrm{HfO}_{2} / \mathrm{SnO}_{2}$ stacks. Before the analysis, both samples were sputter-etched from $\mathrm{HfO}_{2}$ to $\mathrm{SnO}_{2}$ at a slow rate of $0.1 \mathrm{~nm} / \mathrm{s}$. As shown in Figure 3, the Sn $3 d_{5 / 2}$ spectrum of the $\mathrm{SnO}_{\mathrm{x}}$ layer is split into three peaks: $\mathrm{Sn}^{4+}, \mathrm{Sn}^{2+}$, and $\mathrm{Sn}^{0}$. The binding energies of the $\mathrm{Sn}^{4+}, \mathrm{Sn}^{2+}$, and $\mathrm{Sn}^{0}$ peaks were 487, 486.5, and $485.2 \mathrm{eV}$, respectively. The intensity of $\mathrm{Sn}^{2+}$ is related to the p-type SnOTFT [18]. By contrast, $\mathrm{Sn}^{4+}$ conducts electrons for $\mathrm{n}$-type TFTs [11-16]. As the results obtained using XPS analysis do not indicate obvious differences between these two samples, the inserted $\mathrm{SiO}_{2}$ interfacial layer has little effect on the chemical composition of the $\mathrm{SnO}_{\mathrm{x}}$ channel layer. 


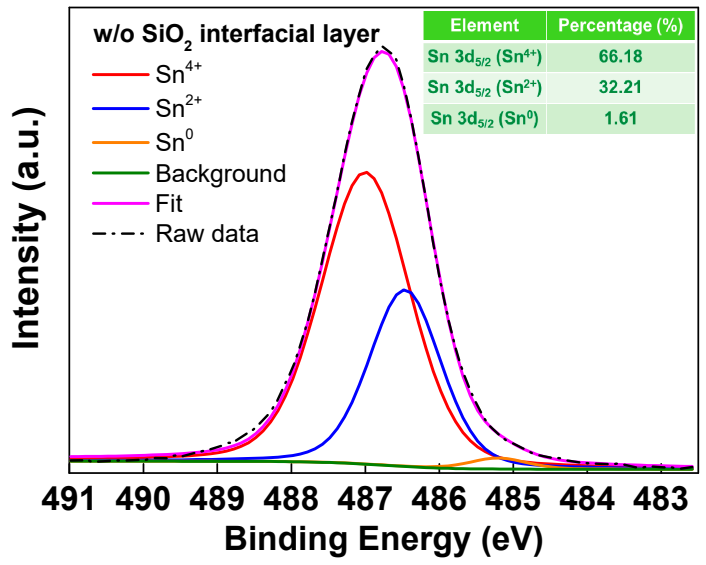

(a)

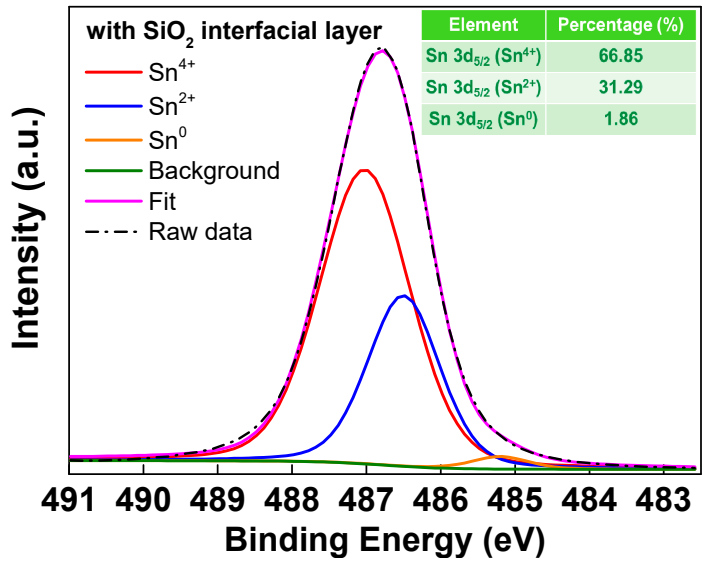

(b)

Figure 3. The XPS spectra of $\mathrm{Sn} 3 \mathrm{~d}_{5 / 2}$ in the $\mathrm{SnO}_{2}$ layer of the TFT devices (a) without and (b) with an $\mathrm{SiO}_{2}$ interfacial layer.

We further investigated the $\mathrm{HfO}_{2} / \mathrm{SiO}_{2} / \mathrm{SnO}_{2}$ stack through TEM and SIMS measurements. Figure 4 a displays the cross-sectional TEM image of the $\mathrm{SnO}_{2}$ TFT with an $\mathrm{SiO}_{2}$ interfacial layer, where the thicknesses of $\mathrm{HfO}_{2}, \mathrm{SiO}_{2}$, and $\mathrm{SnO}_{2}$ were 50,3 , and $4.5 \mathrm{~nm}$, respectively. The distributions of the $\mathrm{Sn}, \mathrm{Si}, \mathrm{Hf}$, and $\mathrm{O}$ atoms in the gate stack and channel layer are depicted from the SIMS depth profiles in Figure 4 b. An $\mathrm{SiO}_{2}$ interfacial layer was clearly observed in both the TEM and SIMS analyses.

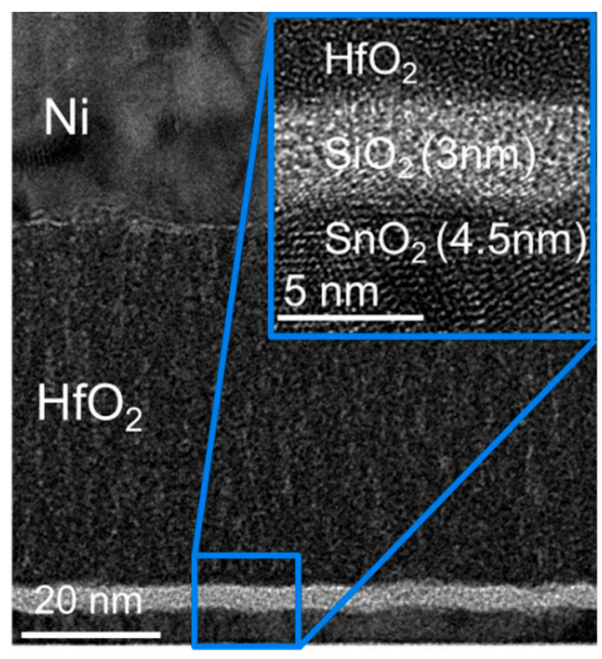

(a)

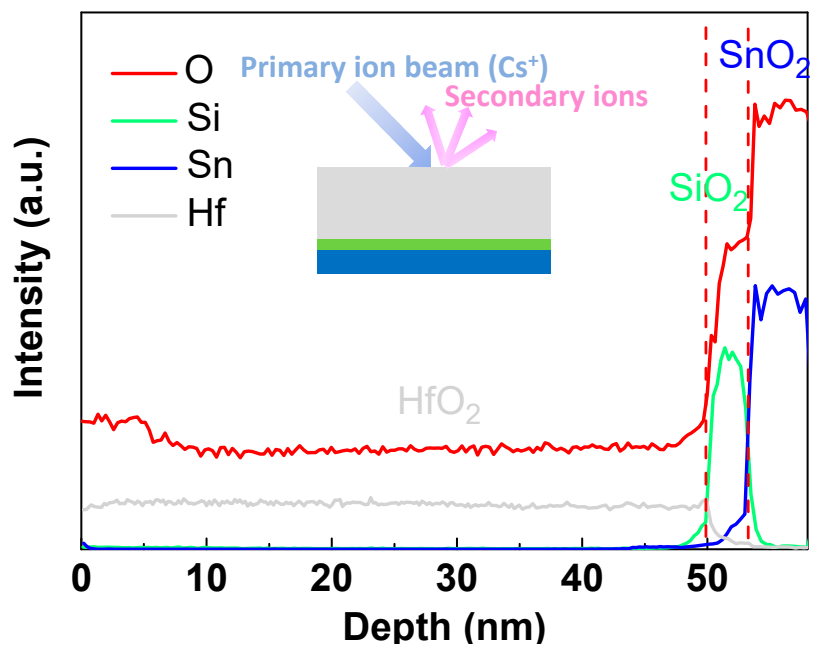

(b)

Figure 4. (a) The cross-sectional TEM image and (b) SIMS depth profiles of the $\mathrm{SnO}_{2}$ TFT with an $\mathrm{SiO}_{2}$ interfacial layer.

It is important to note that the extra $\mathrm{SiO}_{2}$ interfacial layer will increase the thickness of the gate dielectric slightly and theoretically lead to a slightly higher transistor threshold voltage $\left(\mathrm{V}_{\mathrm{TH}}\right)$ than the device without the $\mathrm{SiO}_{2}$ layer. However, the $I_{D S}-V_{G S}$ characteristics of the $\mathrm{SnO}_{2}$ devices in Figure 1a display a contrary result. Thus, the increased $\mathrm{V}_{\mathrm{TH}}$ for the device without the interfacial $\mathrm{SiO}_{2}$ layer is due to the extra negative charges formed in $\mathrm{HfO}_{2}$. These negative charges may also exist in the $\mathrm{HfO}_{2} / \mathrm{SnO}_{2}$ interface because the interface charges are strongly related to $S S$ [22], which improves with the extra $\mathrm{SiO}_{2}$ interfacial layer, as shown in Figure 1a. Further, such negative charges in the $\mathrm{HfO}_{2}$ and $\mathrm{HfO}_{2} / \mathrm{SnO}_{2}$ interfaces can cause electron scattering and degrade the mobility [31,32], as shown in Figure 1b. It is known that the high- $\mathrm{k}$ gate dielectric has defects, especially when formed at low 
temperatures. The negative charges formed in the $\mathrm{HfO}_{2}$ and $\mathrm{HfO}_{2} / \mathrm{SnO}_{2}$ interfaces cause channel electron scattering and mobility degradation, which can be observed in the schematic diagrams illustrated in Figure 5a,b. The device with the $\mathrm{SiO}_{2}$ interfacial layer has less negative charge scattering in $\mathrm{HfO}_{2}$ and the interface because of the separation of the $\mathrm{SiO}_{2}$ layer, which results in a higher mobility and $I_{D S}$.

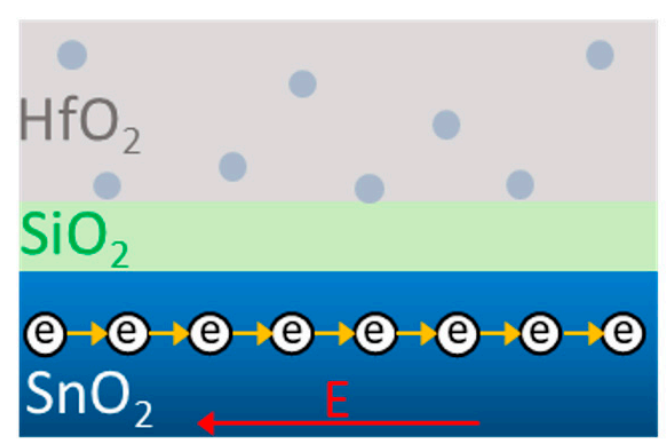

negatively charged defect

(a)

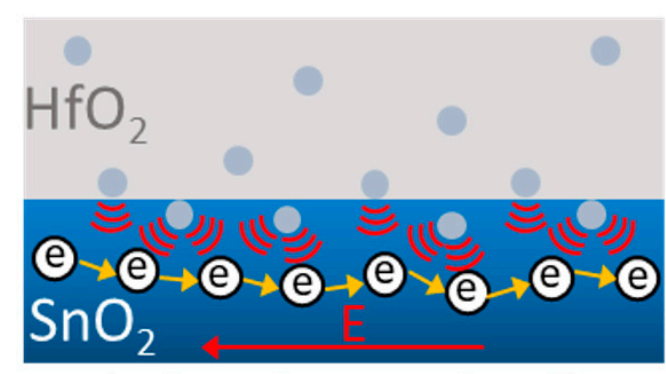

$\longrightarrow$ electron transport path

(b)

Figure 5. The schematic diagrams for electron transport in (a) with (b) without an $\mathrm{SiO}_{2}$ interfacial layer. Negative charges formed in $\mathrm{HfO}_{2}$ for a device without an $\mathrm{SiO}_{2}$ layer will increase the electron scattering and lower the mobility.

The moisture degradation of TFT devices is a significant issue for an IC. Figure 6 illustrates the $I_{D S}-V_{G S}$ characteristics for the as-fabricated top-gate coplanar and bottom-gate staggered $\mathrm{SnO}_{2} \mathrm{TFTs}_{\mathrm{s}}$ ambient air after 7 days and 30 days of exposure to air. The $I_{D S}-V_{G S}$ characteristics of the bottom-gate $\mathrm{SnO}_{2}$ TFT are shifted as high as $1.5 \mathrm{~V}$ after 7 days of exposure, and the $\mathrm{I}_{\mathrm{OFF}}$, $\mathrm{SS}$, and $\mathrm{I}_{\mathrm{ON}}$ further degrade significantly after 30 days of exposure to air. This is because the top $\mathrm{SnO}_{2}$ layer can react with $\mathrm{H}_{2} \mathrm{O}$ molecules in the air and form Sn-OH bonds $[14,19,20]$, resulting in charged defects that lower the $I_{D S}$ and $\mu_{F E}$. The penetration of $\mathrm{OH}^{-}$into the $\mathrm{SnO}_{2}$ could also form defects and lead to a higher $\mathrm{I}_{\mathrm{OFF}}$ by defect conduction [26]. In sharp contrast, only a slight $\mathrm{V}_{\mathrm{TH}}$ shift of $-0.09 \mathrm{~V}$ was observed in the top-gate device because the gate dielectric $\mathrm{HfO}_{2}$ layer can behave as a passivation layer on the $\mathrm{SnO}_{2}$ channel layer. The slight $\mathrm{V}_{\mathbf{T H}}$ shift might be attributed to the intrinsic defects of the $\mathrm{HfO}_{2}$ layer and the charge trapping and de-trapping phenomena of those defects [33,34].

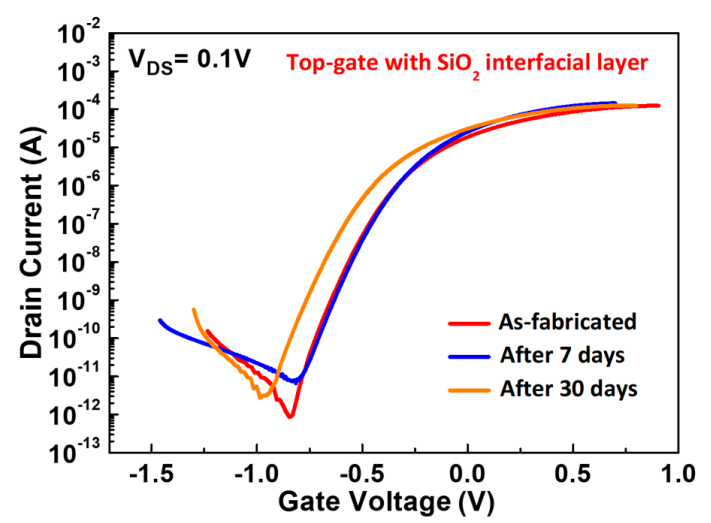

(a)

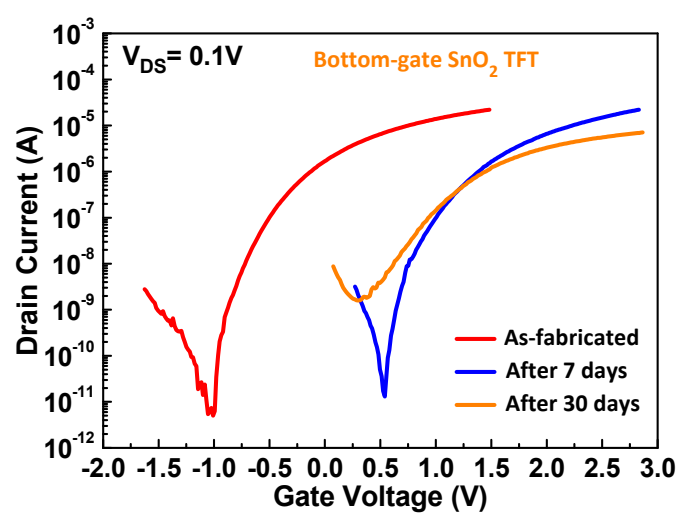

(b)

Figure 6. The $I_{D S}-V_{G S}$ characteristics of the (a) top-gate and (b) bottom-gate $\mathrm{SnO}_{2}$ TFT devices measured as-fabricated after 7 days and after 30 days of exposure to ambient air. 
In Table 1, we summarize the important device characteristics and compare them with the published data on top-gate TFTs made on amorphous $\mathrm{SiO}_{2}$ substrates [21-25]. Our device with an ultra-thin channel thickness of $4.5 \mathrm{~nm}$ exhibits the highest $\mu_{F E}$, a sharp $S S$ for low-voltage operation, and a sufficiently large $\mathrm{I}_{\mathrm{ON}} / \mathrm{I}_{\mathrm{OFF}}$, which are crucial for display, low-leakage DRAM access transistors, and monolithic 3D IC applications. Further improvement of $\mu_{F E}$ and SS may be reachable by using a thicker $\mathrm{SnO}_{2}$ layer than the $4.5 \mathrm{~nm}$ thickness and a Fin Field-Effect Transistor (FinFET) or gate-all-around structure, respectively.

Table 1. Important device performance comparison of various top-gate TFT devices on $\mathrm{SiO}_{2}$ substrate.

\begin{tabular}{ccccc}
\hline $\begin{array}{c}\text { Channel } \\
\text { Materials }\end{array}$ & $\begin{array}{c}\text { Channel } \\
\text { Thickness }(\mathbf{n m})\end{array}$ & $\begin{array}{c}\mu_{F E}\left(\mathbf{c m}^{2} / \mathbf{V} \cdot \mathbf{s}\right) \\
\mathbf{V}_{\boldsymbol{D S}} \mathbf{( V )}\end{array}$ & $\mathbf{I}_{\mathbf{O N}} / \mathbf{I}_{\mathbf{O F F}}$ & SS (mV/Decade) \\
\hline a-Si [21] & 100 & $0.9 @ 0.1$ & $10^{5}$ & 380 \\
Poly-Si [22] & 100 & $40 @ 0.1$ & $1.5 \times 10^{6}$ & 310 \\
$\mathrm{IGZO} \mathrm{[23]}$ & 40 & $11.44 @ 10$ & $10^{8}$ & 360 \\
$\mathrm{ZnO}[24]$ & 50 & $16.8 @ 0.1$ & $2.4 \times 10^{9}$ & 102 \\
$\mathrm{SnO}_{2}[25]$ & 30 & $4.43 @ 1$ & $4.19 \times 10^{6}$ & 300 \\
$\mathrm{SnO}_{2}$ this work & 4.5 & $136 @ 0.1$ & $1.5 \times 10^{8}$ & 108 \\
\hline
\end{tabular}

\section{Conclusions}

An excellent device integrity was achieved for a top-gate TFT made on an amorphous $\mathrm{SiO}_{2}$ substrate using a low process temperature of $350{ }^{\circ} \mathrm{C}$ with a high $\mu_{F E}$ of $136 \mathrm{~cm}^{2} / \mathrm{Vs}$, a sharp SS of $108 \mathrm{mV} / \mathrm{dec}$ for low-voltage operations, and a sufficiently large $\mathrm{I}_{\mathrm{ON}} / \mathrm{I}_{\mathrm{OFF}}$ of $1.5 \times 10^{8}$. Such a top-gate structure is preferred for monolithic IC as compared to bottom-gate devices. In addition, a much better resistance to moisture can be achieved than in the bottom-gate device without passivation. Such a superb device performance is strongly related to the inserted ultra-thin $\mathrm{SiO}_{2}$ layer between the $\mathrm{HfO}_{2}$ and $\mathrm{SnO}_{2}$. The outstanding device performance with top-gate structure is a crucial technology for future-generation high-resolution displays, low-leakage DRAM access transistors, and monolithic 3D brain-mimicking ICs.

Author Contributions: Conceptualization, T.J.Y. and A.C.; supervision, A.C.; co-supervision, V.G. All authors have read and agreed to the published version of the manuscript.

Funding: This research was funded by Ministry of Science and Technology of Taiwan, project no. 107-2221-E-009-092-MY3.

Acknowledgments: We would also like to thank S.F. Liu for assisting with the device fabrication during his Master's degree study.

Conflicts of Interest: The authors declare no conflict of interest.

\section{References}

1. Klasens, H.A.; Koelmans, H. A tin oxide field-effect transistor. Solid State Electron. 1964, 7, 701-702. [CrossRef]

2. Kwon, J.Y.; Son, K.S.; Jung, J.S.; Kim, T.S.; Ryu, A.K.; Park, K.B.; Yoo, B.W.; Kim, J.W.; Lee, Y.G.; Park, K.C.; et al. Bottom-gate Gallium Indium Zinc Oxide thin-film transistor array for high-resolution AMOLED display. IEEE Electron. Device Lett. 2008, 29, 1309-1311. [CrossRef]

3. Xu, H.; Luo, D.; Li, M.; Xu, M.; Zou, J.; Tao, H.; Lan, L.; Wang, L.; Peng, J.; Cao, Y. A flexible AMOLED display on the PEN substrate driven by oxide thin-film transistors using anodized aluminium oxide as dielectric. J. Mater. Chem. C 2014, 2, 1255-1259. [CrossRef]

4. Fortunato, E.; Barquinha, P.; Martins, R. Oxide semiconductor thin-film transistors: A review of recent advances. Adv. Mater. 2012, 24, 2945-2986. [CrossRef]

5. Nomura, K.; Ohta, H.; Takagi, A.; Kamiya, T.; Hirano, M.; Hosono, H. Room-temperature fabrication of transparent flexible thin-film transistors using amorphous oxide semiconductors. Nature 2004, 432, 488-492. [CrossRef]

6. Sekitani, T.; Zschieschang, U.; Klauk, H.; Someya, T. Flexible organic transistors and circuits with extreme bending stability. Nat. Mater. 2010, 9, 1015-1022. [CrossRef] 
7. Su, N.C.; Wang, S.J.; Huang, C.C.; Chen, Y.H.; Huang, H.Y.; Chiang, C.K.; Chin, A. Low-voltage-driven flexible InGaZnO thin-film transistor with small subthreshold swing. IEEE Electron. Device Lett. 2010, 31, 680-682.

8. Zan, H.W.; Li, C.H.; Yeh, C.C.; Dai, M.Z.; Meng, H.F.; Tsai, C.C. Room-temperature-operated sensitive hybrid gas sensor based on amorphous indium gallium zinc oxide thin-film transistors. Appl. Phys. Lett. 2011, 98, 253503. [CrossRef]

9. Kim, K.S.; Ahn, C.H.; Jung, S.H.; Cho, S.W.; Cho, H.K. Toward adequate operation of amorphous oxide thin-film transistors for low-concentration gas detection. ACS Appl. Mater. Interfaces 2018, 10, 10185-10193. [CrossRef]

10. Liao, L.; Zhang, Z.; Yan, B.; Zheng, Z.; Bao, Q.L.; Wu, T.; Li, C.M.; Shen, Z.X.; Zhang, J.X.; Gong, H.; et al. Multifunctional $\mathrm{CuO}$ nanowire devices: P-type field effect transistors and $\mathrm{CO}$ gas sensors. Nanotechnology 2009, 20, 085203. [CrossRef]

11. Shih, C.W.; Chin, A.; Lu, C.F.; Yi, S.H. Extremely high mobility ultra-thin metal-oxide with $n s^{2} n p^{2}$ configuration. Int. Electron. Devices Meeting (IEDM) Technol. Dig. 2015, 145-148. [CrossRef]

12. Chin, A.; Yen, T.J.; Shih, C.W.; Chen, Y.D. High mobility metal-oxide devices for display SoP and 3D brain-mimicking IC. Proc. Int. Disp. Workshops 2019, 26, 455-457. [CrossRef]

13. Chin, A.; Chen, Y.D. Technologies toward three-dimensional brain-mimicking IC architecture. In Proceedings of the 2019 Electron Devices Technology and Manufacturing Conference (EDTM), Singapore, 12-15 March 2019; pp. 472-474.

14. Shih, C.W.; Chin, A. Remarkably High mobility thin-film transistor on flexible substrate by novel passivation material. Sci. Rep. 2017, 7, 1147. [CrossRef] [PubMed]

15. Shih, C.W.; Chin, A.; Lu, C.F.; Su, W.F. Remarkably high mobility ultra-thin-film metal-oxide transistor with strongly overlapped orbitals. Sci. Rep. 2016, 6, 19023. [CrossRef]

16. Shih, C.W.; Yen, T.J.; Chin, A.; Lu, C.F.; Su, W.F. Low-temperature processed tin oxide transistor with ultraviolet irradiation. IEEE Electron Device Lett. 2019, 40, 909-912. [CrossRef]

17. Shih, C.W.; Chin, A. New material transistor with record-high field-effect mobility among wide-band-gap semiconductors. ACS Appl. Mater. Interfaces 2016, 8, 19187-19191. [CrossRef] [PubMed]

18. Shih, C.W.; Chin, A.; Lu, C.F.; Su, W.F. Remarkably high hole mobility metal-oxide thin-film transistors. Sci. Rep. 2018, 8, 889. [CrossRef]

19. Yoo, D.Y.; Chong, E.; Kim, D.H.; Ju, B.K.; Lee, S.Y. Effect of magnesium oxide passivation on the performance of amorphous indium-gallium-zinc-oxide thin film transistors. Thin Solid Film 2012, 520, 3783-3786. [CrossRef]

20. Chowdhury, M.D.H.; Mativenga, M.; Um, J.G.; Mruthyunjaya, R.K.; Heiler, G.N.; Tredwell, T.J.; Jang, J. Effect of $\mathrm{SiO}_{2}$ and $\mathrm{SiO}_{2} / \mathrm{SiN}_{\mathrm{x}}$ passivation on the stability of amorphous indium-gallium zinc-oxide thin-film transistors under high humidity. IEEE Trans. Electron Devices 2015, 62, 869-874. [CrossRef]

21. Han, L.; Huang, Y.; Sturm, J.C.; Wagner, S. Self-aligned top-gate coplanar a-Si:H thin-film transistors with a $\mathrm{SiO}_{2}-$ Silicone hybrid gate dielectric. IEEE Electron Device Lett. 2011, 32, 36-38. [CrossRef]

22. Hung, B.F.; Chiang, K.C.; Huang, C.C.; Chin, A.; McAlister, S.P. High-performance poly-silicon TFTs incorporating $\mathrm{LaAlO}_{3}$ as the gate dielectric. IEEE Electron Device Lett. 2005, 26, 384-386. [CrossRef]

23. Zhang, S.; Shao, Y. Technology issues for self-aligned top-gate amorphous metal oxide thin-film transistors. In Proceedings of the IEEE International Conference on Electron Devices and Solid State Circuits, Shenzhen, China, 6-8 June 2018.

24. Deng, S. Gate Insulator engineering in top-gated indium-tin-oxide-stabilized ZnO thin-film transistors. IEEE Electron. Device Lett. 2019, 40, 1104-1107. [CrossRef]

25. Lim, D.; Jeon, Y.; Kim, M.; Kim, Y.; Kim, S. Electrical characteristics of $\mathrm{SnO}_{2}$ thin-film transistors fabricated on bendable substrates using reactive magnetron sputtering. J. Nanosci. Nanotechnol. 2016, 16, 11697-11700. [CrossRef]

26. Saha, J.K.; Bukke, R.N.; Mude, N.N.; Jang, J. Remarkable Stability Improvement of ZnO TFT with $\mathrm{Al}_{2} \mathrm{O}_{3}$ Gate Insulator by Yttrium Passivation with Spray Pyrolysis. Nanomaterials 2020, 10, 976. [CrossRef]

27. Zhu, S.; Chen, J.; Li, M.-F.; Lee, S.J.; Singh, J.; Zhu, C.X.; Du, A.; Tung, C.H.; Chin, A.; Kwong, D.L. N-type Schottky barrier source/drain MOSFET using ytterbium silicide. IEEE Electron Device Lett. 2004, 25, 565-567. [CrossRef] 
28. Zhu, S.; Yu, H.Y.; Whang, S.J.; Chen, J.H.; Shen, C.; Zhu, C.; Lee, S.J.; Li, M.F.; Chan, D.S.H.; Yoo, W.J.; et al. Schottky-barrier S/D MOSFETs with high-k gate dielectrics and metal gate electrode. IEEE Electron Device Lett. 2004, 25, 268-270. [CrossRef]

29. Chang, M.F.; Lee, P.T.; McAlister, S.P.; Chin, A. Low sub-threshold swing HfLaO/Pentacene organic thin film transistors. IEEE Electron Device Lett. 2008, 29, 215-217. [CrossRef]

30. Kim, M.S.; Kim, H.T.; Chi, S.S.; Kim, T.E.; Shin, H.T.; Kang, K.W.; Park, H.S.; Kim, D.J.; Min, K.S.; Kang, D.W.; et al. Distribution of interface states in MOS systems extracted by the subthreshold current in MOSFETs under optical illumination. J. Korean Phys. Soc. 2003, 43, 873-878. [CrossRef]

31. Fischetti, M.V.; Neumayer, D.A.; Cartier, E.A. Effective electron mobility in Si inversion layers in metal-oxide-semiconductor systems with a high-kappa insulator: The role of remote phonon scattering. J. Appl. Phys. 2001, 90, 4587-4608. [CrossRef]

32. Maitra, K. Impact of metal gates on remote phonon scattering in titanium nitride/hafnium dioxide n-channel metal-oxide-semiconductor field effect transistors-low temperature electron mobility study. J. Appl. Phys. 2007, 102, 114507. [CrossRef]

33. Zafar, S.; Callegari, A.; Gusev, E.; Fischetti, M.V. Charge trapping related threshold voltage instabilities in high permittivity gate dielectric stacks. J. Appl. Phys. 2003, 93, 9298-9303. [CrossRef]

34. Lee, B.H. Intrinsic characteristics of high-k devices and implications of fast transient charging effects (FTCE). In Proceedings of the IEDM Technical Digest. IEEE International Electron Devices Meeting, San Francisco, CA, USA, 13-15 December 2004; pp. 859-862.

Publisher's Note: MDPI stays neutral with regard to jurisdictional claims in published maps and institutional affiliations.

(C) 2020 by the authors. Licensee MDPI, Basel, Switzerland. This article is an open access article distributed under the terms and conditions of the Creative Commons Attribution (CC BY) license (http://creativecommons.org/licenses/by/4.0/). 